\title{
EXPERIMENTAL ANALYSIS ON REDUCED-SCALE PROTECTIVE DOORS
}

\author{
CĂTĂLIN BACIU, MARIN LUPOAE \& DANIEL CONSTANTIN \\ Military Technical Academy, Romania
}

\begin{abstract}
Terrorist events that occurred in the last years changes the global security policy, imposing additional safety measures for building design. Therefore, the protection of access routes should be considered by using protective doors to resist to impact and explosions effects. This paper presents a thorough analysis on establishing a proper configuration to ensure a minimum level of blast protection for metallic doors used for government and military buildings. The analysis includes experimental tests and numerical analysis performed on a 1/3 scale model. Seven different sandwich-type configurations were tested according to specific requirements of actual standards. Each door was successively mounted on a metallic frame, horizontally placed, and a spherical plastic explosive charge, at a standoff distance of $35 \mathrm{~cm}$, was detonated. The deformations were measured on each side of the door, offering the valuable data of their strength capacity and also of the dissipation energy level. The door with a honeycomb interior configuration resulted to be the optimal solution. The numerical results showed a good correlation with numerical ones, permitting the further development of a full-scale model.
\end{abstract}

Keywords: protective doors, blast mitigation, sandwich configuration, metallic frame, honeycomb configuration, scale model.

\section{INTRODUCTION}

Terrorist events over the last decade have determined the revaluation of security policies around the world with regard to the protection of government, military and industrial buildings of vital importance. In this context, the level of protection was increased also in Romania for many types of construction from the national security system [1]. The development of specific activities in safety conditions is also provided by the adoption of appropriate solutions for the protection of the access routes for these constructions.

The state of the art of the protective has shown that there are two main types of doors: metallic explosion-proof doors made of metal plates and special internal structures and explosion-proof doors with a concrete-filled metal structure. The differences between them (the technology used, the resistant pressure levels and the dimensions of the main types of explosion-proof doors) are shown in Table 1 (more details can be found in [1]). The standardized protection levels for explosion-proof doors according to side-on pressure, as well as the mass and standoff distance are presented in [2], [3]. According to the two standards, there are 5 levels of protection for side-on pressure on protective doors, starting from 0.75 bar for level 1 and reaching 6.30 bar for level 5. Also, the incident impulse ranges from 1.05 bar ms to 4.20 bar ms. These values are obtained by the explosion of spherical TNT charges weighing between 3 and $20 \mathrm{~kg}$, placed at a standoff distance from $3 \mathrm{~m}$ to $5.5 \mathrm{~m}$.

The structure inside the door must be lightweight and have a high energy absorption capacity. One of these types of structures could be the sandwich panels. It consists of two thin metallic sheets and a core made of lightweight material such as metal and polymer foam. Thus, the aluminum honeycomb core is a good example of structure in terms of energy absorption ability per unit weight [4], [5]. The inner structures can be also made of curved panels with or without aluminum foam. Chen and Hao [6] and Li et al. [7] investigated the transferring of the blast loads to the supports. Using a uni-directional multi-arch panel, they 
Table 1: Blast doors characteristics.

\begin{tabular}{|c|c|c|c|}
\hline $\begin{array}{l}\text { No. } \\
\text { crt. }\end{array}$ & Technology & Protection level & Dimensions, mm \\
\hline \multirow{2}{*}{1} & \multirow{2}{*}{$\begin{array}{l}\text { Metallic plates and special } \\
\text { internal absorbing structure }\end{array}$} & $\begin{array}{l}\text { Incident pressure } \\
0.2-6.5 \text { bar }\end{array}$ & \multirow{3}{*}{$\begin{array}{l}\text { Varies (as required) } \\
\text { For normal size } \\
\text { protective door: } \\
\text { Width: } 800-1080 \\
\text { Height: } 1800-2100\end{array}$} \\
\hline & & $\begin{array}{l}\text { Reflected overpressure } \\
2-18 \text { bar }\end{array}$ & \\
\hline 2 & $\begin{array}{l}\text { Metallic structure filled } \\
\text { with concrete }\end{array}$ & $\begin{array}{l}\text { Incident pressure } \\
1-25 \text { bar or as required }\end{array}$ & \\
\hline
\end{tabular}

demonstrated that the loads transferred to the supports were reduced because of arch mechanism and the capacity of the panel to withstand blast loads was increased.

This paper presents the results of experimental tests performed on $1 / 3$ scale door model in order to determine the optimal internal configuration for protective doors. Four different sandwich-type configurations were considered, three of them with ribs oriented both on long side and on short side of the doors. Reduced-scale doors were mounted on a metallic frame provided with two hinges. Spherical plastic explosive charges were detonated, at a standoff distance of $35 \mathrm{~cm}$, over each the door horizontally placed, in order to capture their explosive behavior.

\section{SCALING RULES}

Considering the scaling factor $K=1 / 3$, the scaling rules presented in Table 2 were applied to obtain the test configuration.

For the explosive charge, the Hopkinson scaling of blast pressure is used. The scaled standoff distance, $\mathrm{Z}$, is defined as:

$$
Z=R / W^{1 / 3},
$$

where $R$ is the standoff distance and $W$ is the mass of the explosive charge. This means that any configuration of standoff distance and explosive mass that produces the same scaled standoff distance will lead to the same peak value of the pressure.

If it is defined the new standoff distance as $R_{K}=K \cdot R$ and the explosive mass $W_{K}=K^{3} \cdot W$ (the explosive mass is proportional to the explosive volume), then the new scaled standoff distance can be written:

$$
Z_{K}=K \cdot R /\left(K^{3} W\right)^{1 / 3}=R / W^{1 / 3}=Z .
$$

Because the peak pressure depends only on the scaled distance, then the scaled peak pressure will be equal with the full scale peak pressure. The positive time duration and the impulse for the scale model will have the values for full model divided by $W^{1 / 3}$.

Table 2: Scaling relationships.

\begin{tabular}{|l|c|c|c|}
\hline Parameter & Full scale & Scale model & $1 / 3$ scale \\
\hline Length & $L$ & $K \cdot L$ & $L / 3$ \\
\hline Volume & $V$ & $K^{3} \cdot V$ & $V / 27$ \\
\hline Time & $t$ & $K \cdot t$ & $t / 3$ \\
\hline
\end{tabular}




\section{EXPERIMENTAL SETUP}

\subsection{Specimens details}

Seven different $1 / 3$ reduced scale metallic doors were fabricated for experimental session. For the design of door models, a standard $900 \mathrm{~mm} \times 2100 \mathrm{~m}$ door was considered, with characteristics shown in Table 1 . Using the scaling factor $1 / 3$ and the length scaling relationships in Table 2, the dimensions of the scaled model became $300 \mathrm{~mm} \times 700 \mathrm{~mm}$. The dimensions of the L $30 \times 30 \times 3$ steel angles used for fixing on the test metal frame were added and resulted the total dimension of the door leaf as $740 \mathrm{~mm} \times 340 \mathrm{~mm}$ (Fig. 1). The thickness of the sheet metal plates forming the door faces is usually between 8 and $25 \mathrm{~mm}$ [9]. To determine the thickness of the plates for our reduced-scale doors, we combined the results obtained from the real model scaling and the experimental results obtained in [8] to best capture the influence of the sandwich interior structure. Thus, a thickness of $1 \mathrm{~mm}$ for the front plate and $2 \mathrm{~mm}$ for the back plate were chosen.

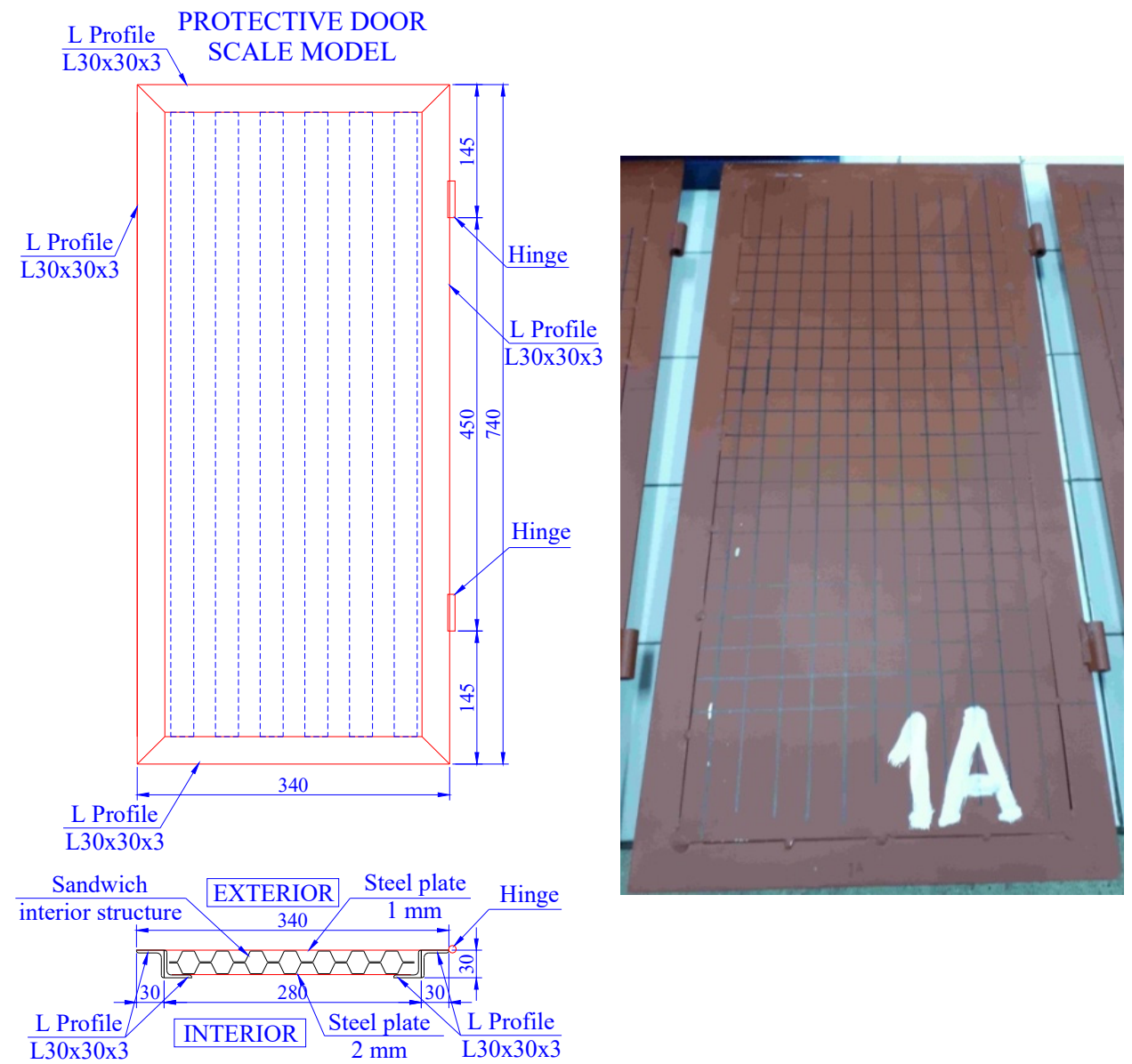

Figure 1: Scale model of protective door (type 1A). 
The edge frame of the door leaf is made of two L30 × $30 \times 3$ steel angles, welded together, both to sustain the steel sheets and to permit the properly fixation on the support frame (Fig. 2). These two steel plates, the front one: $1 \mathrm{~mm}$ thick and the back one: $2 \mathrm{~mm}$ thick, are welded in points on the angles that form the edge frame. The door leaf is mounted on the support frame by two hinges, placed at a distance of $145 \mathrm{~mm}$ from the door edge (Fig. 2). All the components of the door leaves and of the support frame are made of S235 steel.

\subsection{Interior structure}

Four different configurations were used for interior sandwich types (Fig. 3) three of them with ribs orientation on both directions, resulting thus seven specimens.

First interior configuration is made of two profiled sheets, commonly used for building cladding. These two sheets are placed face to face, forming a honeycomb configuration (Fig. 3(a)); they are not connected each other, but only in contact, being free to independently deform. The distance between sheet ribs is $45 \mathrm{~mm}$ and the total thickness of the sandwich is $25 \mathrm{~mm}$. Specimen 1A has the ribs oriented on the long door side and specimen 1B has the ribs oriented on the short side (Table 3).

The second configuration consists of a V-shape cold-formed steel sheet. The distance between V-shape ribs is $45 \mathrm{~mm}$ and the total thickness of the sandwich is $25 \mathrm{~mm}$. Specimen $2 \mathrm{~A}$ has the $\mathrm{V}$-shape ribs oriented on the long door side and specimen $2 \mathrm{~B}$ on the short side (Table 3).

The third sandwich-type door has the interior structure made of corrugated cold formed sheet. The distance between ribs is $60 \mathrm{~mm}$ and the total thickness of the sandwich is $25 \mathrm{~mm}$. Specimen 3A has the ribs oriented on the long door side and specimen 3B on the short side (Table 3). The thickness of all the steel sheets, used for all the internal structures above presented is $0.4 \mathrm{~mm}$.

The fourth sandwich-type door has the interior structure made of UD $30 \times 0.6$ profile, commonly used to from structural frames for gypsum board walls. The profiles are placed on both orthogonal directions: one on the long side, in the middle of the door leaf, and other two on the short side, at a distance of $200 \mathrm{~mm}$ from the edge.

For all the doors, the internal structure is connected neither to the exterior sheets, nor to the edge frame.

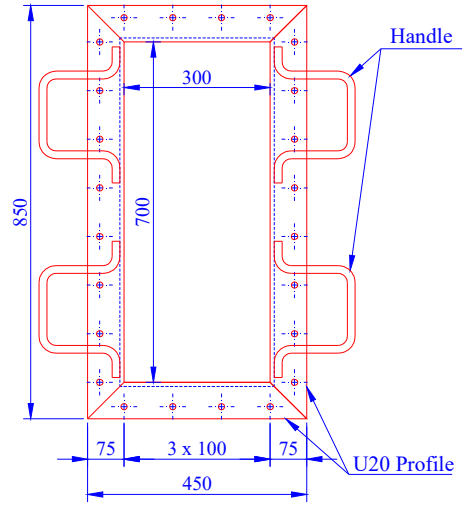

(a)

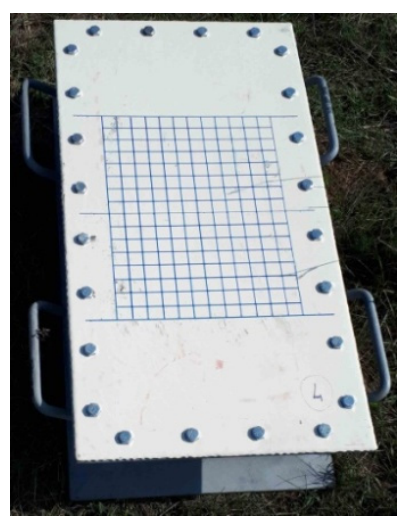

(b)

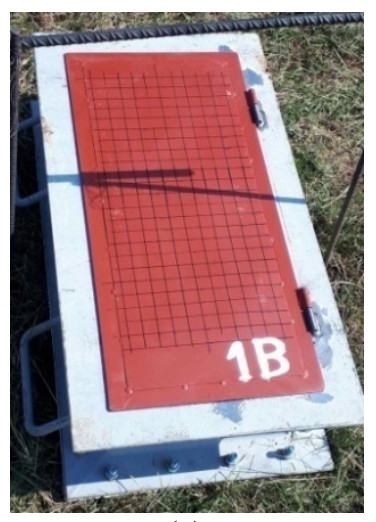

(c)

Figure 2: Steel support frame. (a) Sketch of the frame; (b) Front face; and (c) Back face. 
TYPE 1 CONFIGURATION
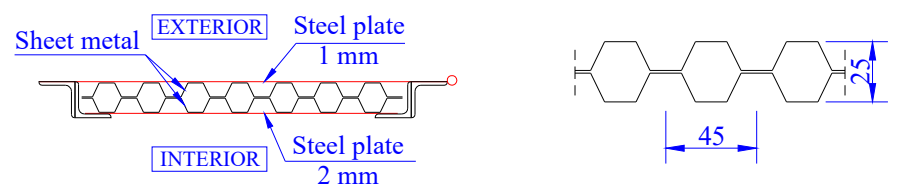

(a)

TYPE 2 CONFIGURATION
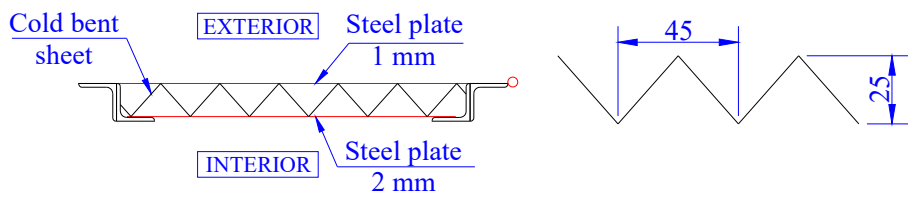

(b)
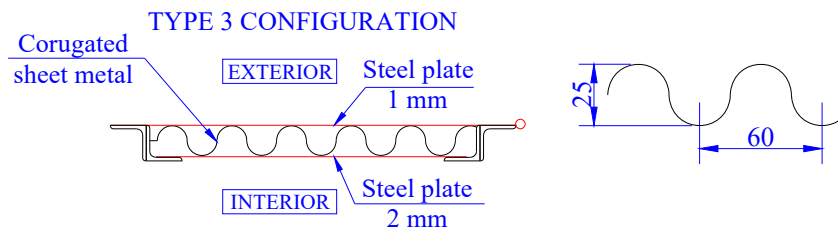

(c)

TYPE 4 CONFIGURATION

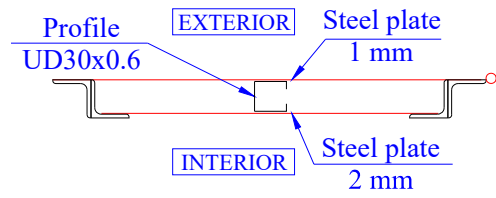

(d)

Figure 3: Interior structure configuration. (a) Honeycomb configuration; (b) V-shape configuration; (c) Corrugated sheet configuration; and (d) Profile UD configuration.

Table 3: Testing specimens.

\begin{tabular}{|c|c|c|c|c|}
\hline $\begin{array}{c}\text { Test } \\
\#\end{array}$ & Configuration type & Ribs orientation & $\begin{array}{l}\text { Explosive } \\
\text { charge, g }\end{array}$ & $\begin{array}{c}\text { Standoff, } \\
\mathrm{cm}\end{array}$ \\
\hline $1 \mathrm{~A}$ & Tyne 1 Honeycomb & Long side (LSo) & \multirow{7}{*}{250} & \multirow{7}{*}{35} \\
\hline $1 \mathrm{~B}$ & гуре 1- попеусопо & Short side (SSo) & & \\
\hline $2 \mathrm{~A}$ & \multirow{2}{*}{ Type 2 - V-shape sheet } & Long side (LSo) & & \\
\hline $2 \mathrm{~B}$ & & Short side (SSo) & & \\
\hline $3 \mathrm{~A}$ & \multirow{2}{*}{ Type 3 -Corrugated sheet } & Long side (LSo) & & \\
\hline $3 \mathrm{~B}$ & & Short side (SSo) & & \\
\hline 4 & Type 4 - UD Profiles & - & & \\
\hline
\end{tabular}




\subsection{Steel support frame}

The door leaves were tested on a support (Fig. 2) made of U20 hot rolled steel profiles, welded to form a frame with interior dimensions, $300 \mathrm{~mm}$ x $700 \mathrm{~mm}$. The frame was designed so it permits to test simple steel sheets on one side and door leaves hinged on the opposite side (with pins welded on frame and the knuckles on the door leaves).

\subsection{Test setup}

For each door, a 250 grams spherical plastic explosive charge was detonated, at a standoff distance of $35 \mathrm{~cm}$ (Fig. 4). The explosive charge mass was chosen taking into account the results presented in [8], while the standoff distance of $35 \mathrm{~cm}$ was considered in order to permit of the scale model of the doors to deform enough to determine the influence of different interior structures. According to the test results [8], it occurred that a $1 \mathrm{~mm}$ thick plate of the same material (S235 steel) used for small-scale models, under detonation of $120 \mathrm{~g}$ plastic explosive at a standoff distance of $20 \mathrm{~cm}$ had a maximum deformation of 17.84 $\mathrm{mm}$. To clearly capture the attenuation capacity of the internal structure, the amount of explosives was increased to 250 grams and standoff distance was set to be greater than the range of the explosion products, which is about 10-12 radii of the explosive charge [10], resulting in a standoff distance of $35 \mathrm{~cm}$. Thereby it was obtained a proper configuration explosive mass - standoff distance that induce sufficient deformation of the upper plate that can permit a correct measurement, thus a good interpretation of the attenuation capacity of the internal structure; on the other hand, the target must remain outside the action distance of detonation products. In this way, loading on reduced-scale models is produced only by shock wave, just as real-scale testing.

In a horizontal plane, the charge projection is located in the centre of the door leaf. The charge weight was established so that to produce important deformations of the doors, permitting to easily compare their behaviour. The charge weight corresponds also to testing results obtained on $2 \mathrm{~mm}$ thick simple steel sheets. Sheets were fixed on contour on the frame support with bolts and a 120 grams explosive charge was detonated at a $20 \mathrm{~cm}$ stand-off distance. An $18 \mathrm{~mm}$ maximum deformation was measured [8].

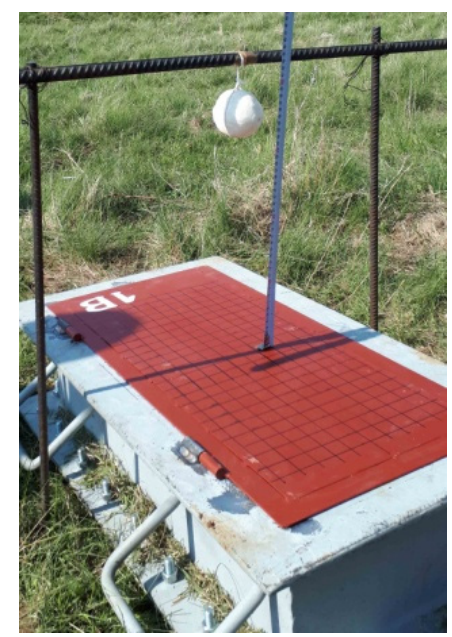

Figure 4: Explosive test setup. 
Testing specimens are listed in Table 3. On every front sheet a net is drawn (Fig. 1) to thoroughly measure the deformations of the door leaves after explosive charge detonation; the distances between net lines are $25 \mathrm{~mm}$.

\section{RESULTS AND DISCUSIONS}

\subsection{Superior (front) steel plate}

The maximum values of superior plates deformation (those directly exposed to detonation) are presented in Table 4. For the established configuration charge weight - stand-off distance, the action of the shock wave produced important deformations of the superior plates on a significant area. This can be observed on the door images after the test (on both of their sides) (Fig. 5) but more obviously on the deformation of the front plate obtained by measuring the displacements of the net points drawn on it (Fig. 6).

The highest value of the superior plate maximum deformation is $44.28 \mathrm{~mm}$, on the Type 4 and the smallest maximum deformation is $19.53 \mathrm{~mm}$, on the Type 1A. The internal structure directly influences the deformation of superior plates; for example, for the type $2 \mathrm{~A}$ and $2 \mathrm{~B}$, the traces of internal $\mathrm{V}$-shape sheet could be easily observed on the surface of superior plate.

\subsection{Inferior (back) steel plate}

Maximum displacements of inferior plate are presented in Table 4 and the images of deformation are shown in Figs 5 and 6. The different internal structures influence both the deformations of superior and inferior plates. The highest value of the inferior plate maximum deformation is $50.82 \mathrm{~mm}$, measured on the Type 4 and the smallest maximum deformation is $14.03 \mathrm{~mm}$, on the Type $2 \mathrm{~B}$.

In terms of maximum deformations, the highest values for both superior and inferior plates are measured for the same door, Type 4, showing that this configuration has the smallest strength capacity. On the other hand, the smallest values of maximum deformations are not measured for the same door: Type 1A for superior plate and Type $2 \mathrm{~B}$ for inferior plate. The dissipation capacity of internal structures directly influences the deformations of the door leaves.

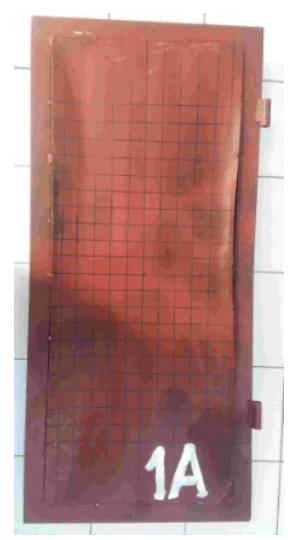

(a)

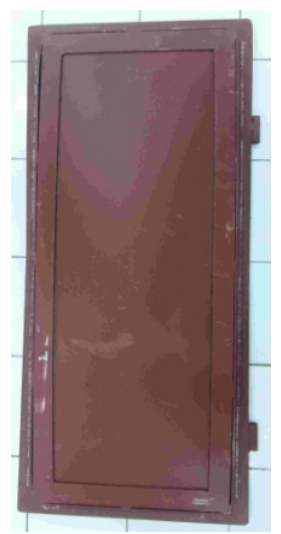

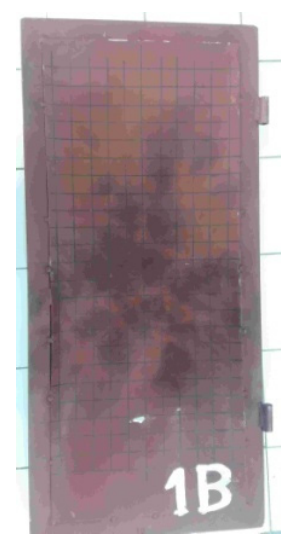

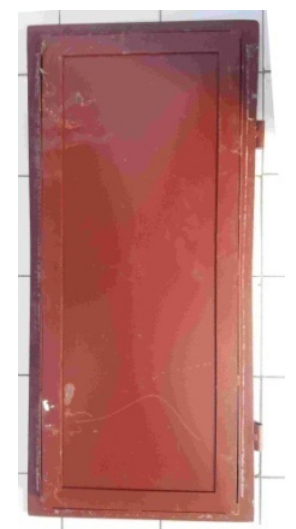

(b)

Figure 5: The deformation of the doors. (a) Type 1A configuration-long side orientation (LSo); and (b) Type 1B configuration-short side orientation (SSo). 


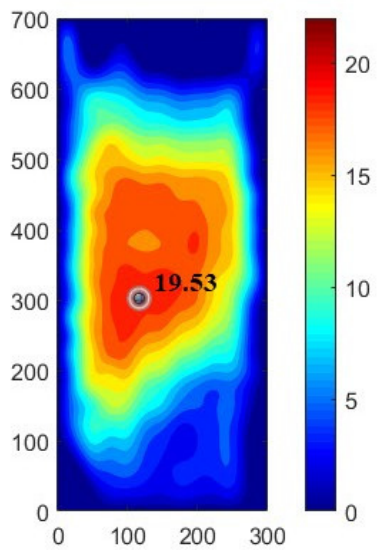

(a)

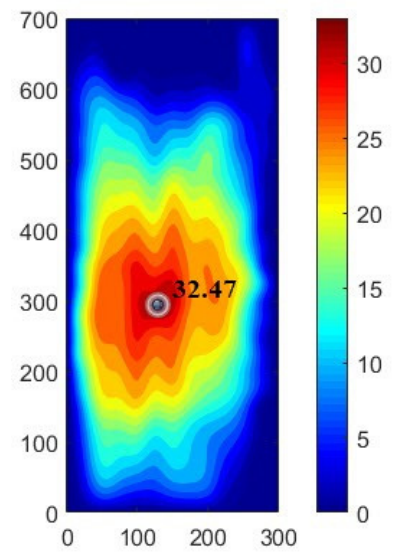

(c)

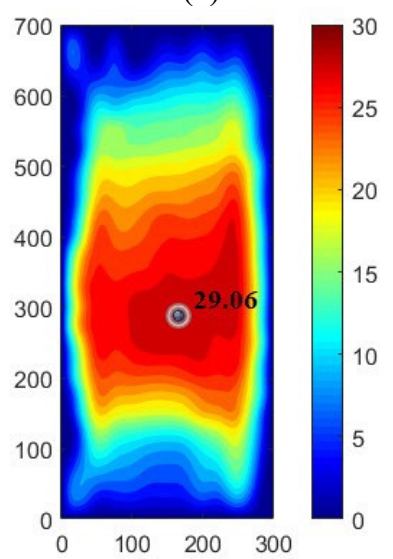

(e)

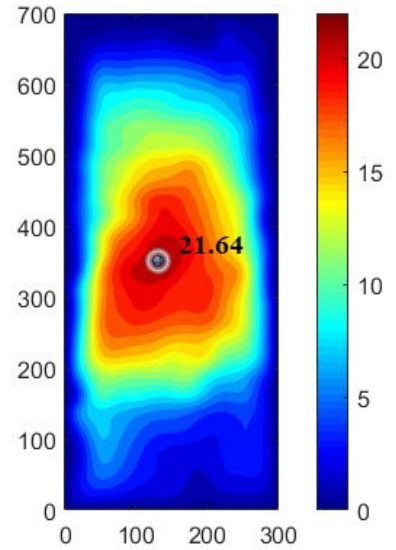

(b)

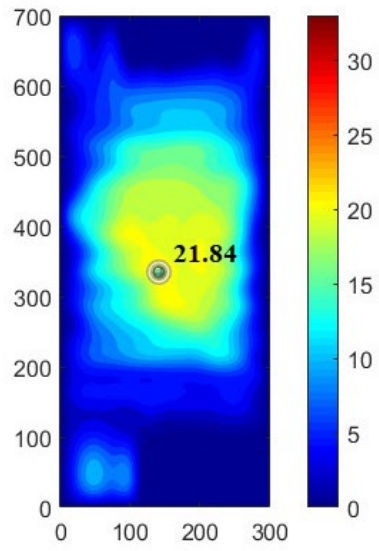

(d)

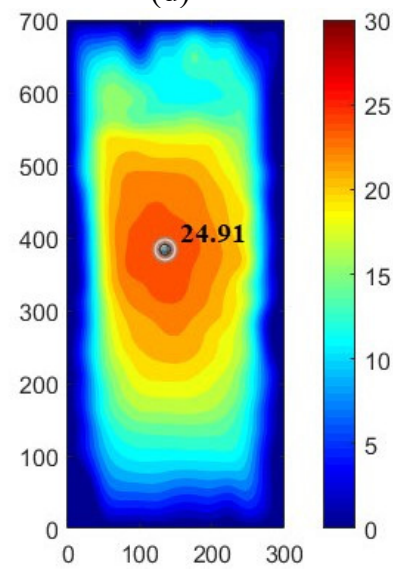

(f)

Figure 6: The post-processed deformation of the front plate of the doors. (a) Type 1ALSo; (b) Type 1B-SSo; (c) Type 2A-LSo; (d) Type 2B-SSo; (e) Type 3A-LSo; and (f) Type 3B-SSo. All dimensions are in millimetres. 
Table 4: Maximum deformations of the front and back plates of the doors.

\begin{tabular}{|c|l|l|c|c|c|}
\hline \multirow{2}{*}{$\begin{array}{c}\text { Test } \\
\#\end{array}$} & \multirow{2}{*}{ Configuration type } & $\begin{array}{c}\text { Ribs } \\
\text { orientation }\end{array}$ & $\begin{array}{c}\text { Front plate } \\
\text { maximum } \\
\text { deformation, } \\
\mathrm{mm}\end{array}$ & $\begin{array}{c}\text { Back plate } \\
\text { maximum } \\
\text { deformation, } \\
\text { mm }\end{array}$ & $\begin{array}{c}\text { Difference } \\
\text { between front } \\
\text { and back plate } \\
\text { deformation, mm }\end{array}$ \\
\hline 1A & \multirow{2}{*}{ Type 1 - Honeycomb } & Long side & 19.53 & 14.63 & 4.84 \\
\cline { 3 - 6 } 1B & Short side & 21.64 & 18.39 & 4.49 \\
\hline 2A & \multirow{2}{*}{$\begin{array}{l}\text { Type 2 - V-shape } \\
\text { sheet }\end{array}$} & Long side & 32.47 & 22.08 & 11.45 \\
\cline { 3 - 6 } & Short side & 21.84 & 14.03 & 7.33 \\
\hline 3A & $\begin{array}{l}\text { Type 3 - Corrugated } \\
\text { sheet }\end{array}$ & Long side & 29.06 & 24.52 & 5.14 \\
\cline { 2 - 6 } & Short side & 24.91 & 20.00 & 3.76 \\
\hline 4 & Type 4 - UD Profiles & - & 44.28 & 50.82 & 6.54 \\
\hline
\end{tabular}

\subsection{Interior sandwich configuration}

\subsubsection{Influence of the interior structure shape}

The influence of the interior structure shape can be firstly determined analysing the difference between the maximum displacements of superior plate and inferior ones. With no internal structure or with low resistance internal structure (the case of Type 4), the deformations of both plates are important: $44.28 \mathrm{~mm}$ - for superior plate, $50.82 \mathrm{~mm}$ - for inferior plate.

The values of the difference between the maximum displacements of superior plate and inferior ones presented in the last column of Table 4, show that the Type 3B has the best dissipation capacity. Due to the rounded shape, this type of structure can better distribute the internal efforts, as a result of the buckling plastic deformation at the middle of at the height of the profile.

Another interesting result is that the smallest values for superior and inferior plates are not measured for the same door type: for the superior plate - Type 1A with $19.53 \mathrm{~mm}$, for the inferior plates - Type 2B with $14.03 \mathrm{~mm}$. Thus, the interior structure shape significantly influences the behaviour of the door leaves under extreme loadings.

The strength capacity of the tested doors can be directly determined analysing the values of displacements measured both on superior and inferior plates (the smallest value represents the higher strength capacity and vice versa). On the other hand, the difference between the displacements measured on opposite sides of the same door refers to the capacity to dissipate energy (the higher the difference is, the higher the capacity of absorption energy is). $\mathrm{V}$-shape internal configurations, Type $2 \mathrm{~A}$ and Type $2 \mathrm{~B}$, determine the highest differences between displacements measured on opposite sides.

Taking into consideration the criterion of strength capacity that gives the smallest maximum displacements of the front plate, Type 1A was the best door model, with 19.47 $\mathrm{mm}$. On the other hand, considering the criterion of energy dissipation capacity, Type 3B offered the best results.

\subsubsection{Influence of the ribs orientation}

Analysing the deformations of the superior and the inferior plates according to ribs orientation of internal structures, it results that the stiffness is higher (and the displacements are smaller) when the ribs are oriented on the short side direction - for Type 2 and Type 3. The exception is the Type 1, where the honeycomb ribs oriented on the long side direction (Type 1A) provide smaller displacements for both superior and inferior plates, comparing to Type 1B. 

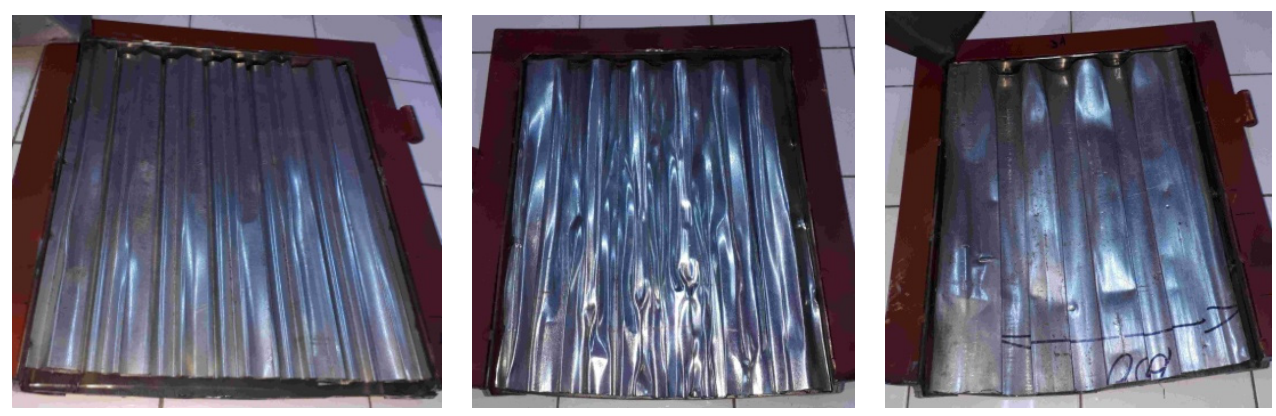

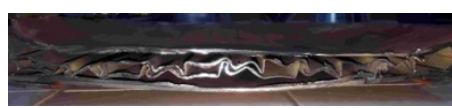

(a)

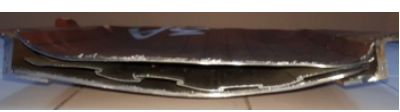

(b)

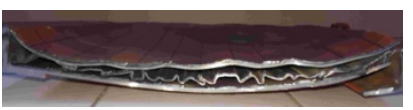

(c)

Figure 7: The deformation of interior structure. (a) Type 1A; (b) Type 2A; and (c) Type 3A.

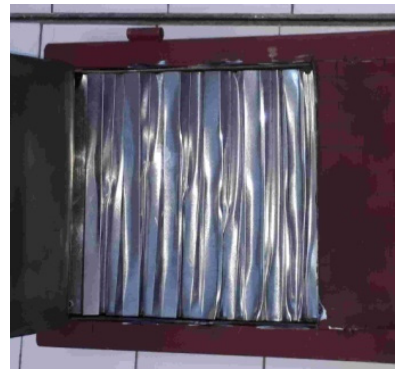

(a)

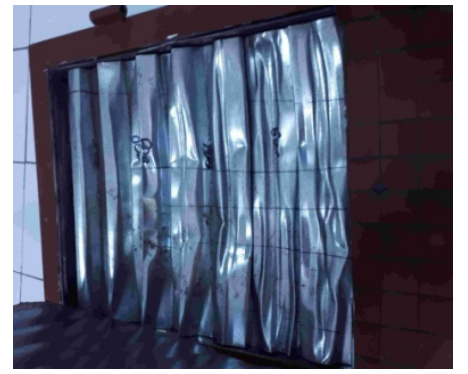

(b)

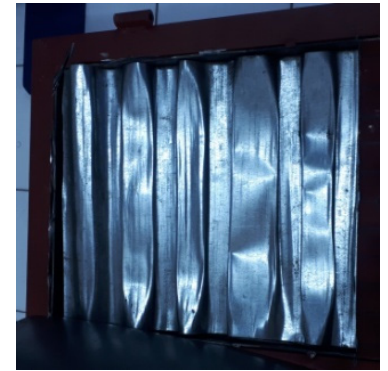

(c)

Figure 8: The deformation of interior structure. (a) Type 1B; (b) Type 2B; and (c) Type 3B.

Analysis of the differences between the maximum deformation values on the two sides of the door for the same configuration, shows, as expected, that the differences are higher for the orientation of the ribs in the long direction of the door compared to their orientation in the short direction (for the Type 1 the difference between the deformations for the arrangement of the ribs along the long side is $4.84 \mathrm{~mm}$ compared to $4.49 \mathrm{~mm}$ in the short direction).

\section{CONCLUSION}

The present paper presents the results of experimental tests performed on 1/3 scale model of protective doors, aiming to determine the configuration able to attenuate the shock wave in the best conditions. Four different sandwich-type door leaves were tested (Type 1 Honeycomb, Type 2 - V-shape sheet, Type 3 - Corrugated sheet, Type 4 - UD Profiles), first three with ribs oriented on both orthogonal directions. The specimens were subjected to the detonation of an explosive charge, placed at the centre of the superior plate of the door, at a stand-off distance of $35 \mathrm{~cm}$.

The analysis showed that the best results are obtained for Type 1A (for the highest resistance capacity) and Type 3B (for the greatest amount of dissipated energy). Thus, the 
interior structure of Type 1 determines the smallest deformation of the superior plate, but a higher deformation for the inferior plate due to the higher height of the interior structure after deformation. The Type 3 configuration provides lower deformation of the inferior plate due to the deformation of the structure, but also a higher deformation of the superior plate. When comparing the maximum displacements of the superior and inferior plates for Type 1 and Type 3 with the same orientation of the ribs, valuable information on the attenuation capacity of the interior structure of the doors can be obtained. Given the almost identical conditions regarding the test mode and the characteristics of the doors, it appears that the Type 3 configuration seems best suited to the shock wave attenuation. However, depending on the technical conditions the door has to meet, the deformation of the front side of the door from the explosive charge may be important (e.g. the tightness condition after the explosion).

Our future research will focus on determining the influence of the connection of internal structure with inferior plate and of the attachment of sheets to each other for Type 1.

\section{ACKNOWLEDGEMENT}

This paper has been financially supported within the Bridge Grant project entitled "Protection System against Explosion, Chemical and Biological Agents for Buildings", registration code PN-III-P2-2.1- BG-2016-0370, contract number 52BG/2016.

\section{REFERENCES}

[1] Lupoae, M., Baciu, C. \& Constantin, D., Aspects regarding the blast loads on protective doors. MTA Review, 27(1), pp. 20-25, 2017.

[2] EN 13123-2:2007, Windows, doors and shutters. Explosion resistance. Requirements and classification. Part 2: Range test, ASRO, 2004.

[3] EN 13124-2:2004, Windows, doors and shutters. Explosion resistance. Test method. Part 2: Range test, ASRO, 2004.

[4] Karagiozova, D., Nurick, G.N., Langdon, G.S., Chung Kim Yuen, S., Chi, Y. \& Bartle, S., Response of flexible sandwich-type panels to blast loading. Composites Science and Technology, 69(6), pp. 754-763, 2009.

[5] Zhu, F., Lu, G., Ruan, D. \& Wang, Z., Plastic deformation, failure and energy absorbtion of sandwich structures with metallic cellular cores. International Journal of Protective Structures, 1(4), pp. 507-541, 2010.

[6] Chen, W. \& Hao, H., Experimental investigations and numerical simulations of multiarch double-layered panels under uniform impulsive loadings. International Journal of Impact Engineering, 63(1), pp. 140-157, 2014.

[7] Li, Z., Chen, W. \& Hao, H., Numerical study of sandwich panel with a new bidirectional Load-Self-Cancelling (LSC) core under blast loading. Thin-Walled Structures, 127(6), pp. 90-101, 2018.

[8] Baciu, C., Lupoae, M., Constantin, D. \& Casapu, A., Experimental and numerical analysis of scale model protective door under blast loadings. Proceedings of Research for an International Conference, Edinburgh, UK, pp. 1-4, 2017.

[9] Baciu, C., Lupoae, M. \& Constantin, D., Protection System Against Explosion, Chemical And Biological Agents For Buildings-Phase I. Technical Report, Military Technical Academy, Bucharest, 2016. (In Romanian.)

[10] Henrych, J., The Dynamics of Explosion and its Use, Elsevier: Amsterdam, 1979. 